\title{
Linear growth in prepubertal children with atopic dermatitis
}

\author{
L Patel, P E Clayton, G M Addison, D A Price, T J David
}

\begin{abstract}
Objective-To define the evolution of prepubertal growth in atopic dermatitis and the factors influencing that growth pattern.

Methods-Height and height velocity over two years, weight, triceps and subscapular skin fold thickness, and bone age were assessed in 80 prepubertal patients with atopic dermatitis and a control group of 71 healthy prepubertal school children. Results-Height standard deviation scores (SDS) and height velocity SDS did not differ between patients and controls, and were not influenced by body surface area affected by atopic dermatitis, topical glucocorticoid potency, or coexisting asthma. However, height SDS $(r=-0.37)$ and height velocity SDS $(r=-0.31)$ correlated inversely to age in patients but not in controls. A greater proportion $(z=2.84)$ of patients than controls had year 2 height velocity SDS less than -1.96 . Patients had a mean delay in bone age of 0.22 years and 0.41 years at the beginning of year 1 and year 2 of the study, respectively. The delay in bone age correlated positively with age $(r=0.39)$ and duration of atopic dermatitis $(r=0.39)$, and negatively with height SDS $(r=-0.51)$ and height velocity SDS $(r=-0.38)$.

Conclusions-Prepubertal children with atopic dermatitis are not short compared with controls. However, as they approach the teenage years their height velocity decreases, the proportion of children with extremely low height velocity increases, and the delay in bone age increases. These features are consistent with the pattern of growth seen in people with constitutional growth delay.
\end{abstract}

(Arch Dis Child 1998;79:169-172)

Keywords: atopic dermatitis; growth; height; height velocity

hildren's Hospita

Manchester M9 7AA,

UK

L Patel

P E Clayton

D A Price

T J David

Paediatric

Biochemistry

Department,

Manchester Children's

Hospital Trust,

Manchester, UK

G M Addison

Correspondence to: Dr Patel.

Accepted 13 March 1998 as the disease itself, sleep disturbance, ${ }^{6}$ impaired growth hormone release, ${ }^{7}$ topical glucocorticoid treatment, undernutrition, ${ }^{8}$ and coexisting asthma and its treatment have not been determined.

Our study aimed to define the evolution of prepubertal growth in atopic dermatitis and the factors influencing that growth pattern. Constitutional delay of growth and puberty is a common cause of short stature and is defined as height reduced for chronological age associated with delayed bone age and delayed pubertal development in otherwise healthy adolescents. ${ }^{9}$ However, this pattern of delayed growth has often been present throughout childhood..$^{10}$ Thus, retarded linear growth and retarded bone age are likely in the prepubertal years in children with constitutional delay. We hypothesised that prepubertal children with atopic dermatitis would have this pattern of growth and exhibit: (1) a lower height velocity than controls, (2) a decrease in height velocity over time (retarded linear growth), and (3) delayed bone age.

\section{Subjects and methods}

We recruited 80 consecutive prepubertal children (mean age, 4.8 years; range, 2.0-10.5) attending the University Department of Child Health for atopic dermatitis from October 1992 to June 1993, referred by paediatricians or dermatologists because of the severity or intractable nature of the disease. Prepubertal patients aged 2-11 years whose atopic dermatitis appeared in the first year of life, irrespective of severity, were eligible for the study. The parents of one child declined participation. We excluded two patients treated with systemic glucocorticoids.

For each of the first 40 patients with atopic dermatitis aged $\geqslant 3$ years, two control subjects of the same sex and age (birth date, as recorded in the school register, within one month of that of the patient) were enrolled from two local schools (there were no children under 3 years of age in the schools). Of these 80 school children, nine were excluded (two had a history of atopic dermatitis and asthma, five left the school within six months of the start of the study, and two were repeatedly absent from school). Thus, we studied 71 non-atopic children.

There were no children with a known independent cause for short stature, history of chronic systemic disease, or endocrine problem in the study or control groups. The study was approved by the local ethics committee and informed consent was obtained from parents and children old enough to understand. 
Table 1 Scores for severity of atopic dermatitis, topical glucocorticoid treatment, and coexisting asthma

\begin{tabular}{|c|c|c|c|c|}
\hline Score for severity of atopic dermatitis (total 9) & 1 & 2 & 3 & \\
\hline Body surface area involved & $<9 \%$ & $9-36 \%$ & $>36 \%$ & \\
\hline Erythema & Mild & Moderate & Severe & \\
\hline Course & Remission $>3$ months in past year & Remission $<3$ months in past year & Continuous & \\
\hline Score for topical glucocorticoid treatment (total 10) & 1 & 2 & 3 & 4 \\
\hline Potency of preparation & Mild & Moderate & Potent & Very potent \\
\hline Body surface area treated & $<9 \%$ & $9-36 \%$ & $>36 \%$ & \\
\hline Treatment duration & $\leqslant 7$ days in past month & $<7$ days in past month & Continuous & \\
\hline Score for coexisting asthma (total 8) & 0 & 1 & 2 & 3 \\
\hline Number of exacerbations in a year & 0 & $1-3$ & $4-6$ & $\geqslant 7$ \\
\hline Interval symptoms & None & Intermittent & Continuous & - \\
\hline Treatment & None & Bronchodilators & Sodium cromoglycate & $\begin{array}{l}\text { Inhaled } \\
\text { glucocorticoid }\end{array}$ \\
\hline
\end{tabular}

For the patients with atopic dermatitis, we recorded age of onset, percentage body surface area involved, and potency of topical glucocorticoid preparation used as described in the British National Formulary. Patients had mild to severely inflamed atopic dermatitis involving $8-95 \%$ (median, $47 \%$ ) of the body surface area. The severity of atopic dermatitis, treatment, and asthma scores were based on the criteria shown in table 1 . Thirty eight patients regularly used mild potency topical glucocorticoid preparations and 39 patients used moderate potency preparations. Only one patient regularly used a potent topical glucocorticoid preparation. Two patients did not use topical glucocorticoid preparations.

Height velocity for year 1 and year 2 of the study was calculated from height measurements taken 12 months apart. Height was measured with a wall mounted Harpenden stadiometer using a standard protocol. ${ }^{11}$ The standard deviation of the difference between blind triplicate height measurements of 10 children was $0.12 \mathrm{~cm}$. Weight (child lightly clothed) and triceps and subscapular skin fold thickness (skin fold thickness calipers) were measured. To standardise data for age and sex, standard deviation scores (SDS) were calculated for height and height velocity (using Tanner, Whitehouse, and Takaishi standards ${ }^{12}$ ) and body mass index (BMI) (using Cole, Freeman, and Preece standards ${ }^{13}$ ). Values less than -1.96 SDS below the mean were considered to be extremely low. Bone age was assessed from left wrist radiographs using the TW2 method ${ }^{14}$ on the children with atopic dermatitis at the start of year 1 and year 2 of the study.

Variables were compared between: (1) children with atopic dermatitis who had $<50 \%$ body surface area involvement $(n=43)$ and those with $\geqslant 50 \%$ body surface area involve- ment ( $\mathrm{n}=37)$; (2) children with atopic dermatitis treated with mild potency $(n=38)$ and moderate potency $(n=39)$ topical glucocorticoids; (3) children with atopic dermatitis without asthma $(\mathrm{n}=36)$ and those with asthma $(n=44)$; and (4) the subgroup of children with atopic dermatitis aged $\geqslant 3$ years $(n=62$; mean age, 5.5 years; range, 3.0-10.5) and a control group of healthy school children ( $n=71$; mean age, 5.8 years; range, 3.2-9.9).

Height, height velocity, and BMI SDS were normally distributed. Triceps and subscapular skin fold thickness and body surface area involved were logarithmically transformed. The two sample $t$ test was used for analysis and 95\% confidence intervals are given to indicate the magnitude of the difference and to take risks of type II errors into account. Proportions were compared using the $\mathrm{z}$ statistic. Correlation and regression analysis were used to investigate the relation between the growth parameters and independent variables. The number of children completing one year and two year follow up were 53 and 36 for the patient group and 70 and 64 for the control group, respectively. The growth parameters and atopic dermatitis parameters at study entry were not different between the patients who completed the study and those who were lost to follow up.

\section{Results}

HEIGHT AND HEIGHT VELOCITY IN PATIENTS WITH ATOPIC DERMATITIS COMPARED WITH CONTROLS

There were no significant differences in age and height SDS at study entry between patients and controls (table 2). The heights at study entry of one of the 62 patients and three of the 71 controls were less than -1.96 SDS of the mean. At the end of the study, one patient

Table 2 Variables for patients with atopic dermatitis aged $\geqslant 3$ years and controls

\begin{tabular}{|c|c|c|c|}
\hline & Atopic dermatitis & Controls & $95 \% C I^{\star}$ \\
\hline Number (boys/girls) & $62(34 / 28)$ & $71(39 / 32)$ & \\
\hline Mean (SEM) age in years & $5.52(0.29)$ & $5.83(0.26)$ & $0.4(-0.46,1.09)$ \\
\hline Mean (SEM) height SDS at study entry & $0.11(0.13)$ & $-0.03(0.11)$ & $0.4(-0.48,0.21)$ \\
\hline Mean (SEM) height SDS after 2 years & $-0.10(0.18)$ & $-0.03(0.12)$ & $0.8(-0.38,0.51)$ \\
\hline Mean (SEM) year 1 height velocity SDS & $-0.10(0.18)$ & $-0.09(0.11)$ & $1.0(-0.43,0.43)$ \\
\hline Mean (SEM) year 2 height velocity SDS & $-0.31(0.27)$ & $0.06(0.12)$ & $0.2(-0.22,0.96)$ \\
\hline Mean (SEM) body mass index SDS & $0.48(0.15)$ & $0(0.13)$ & $0.01(0.10,0.86)$ \\
\hline Median triceps skinfold thickness (mm) (interquartile range) & $10.7(8.2-13.9)$ & $11.2(9.7-13.6)$ & $0.2(-0.02,0.09)$ \\
\hline Median subscapular skinfold thickness (mm) (interquartile range) & $6.2(5.2-7.8)$ & $5.7(5.0-7.2)$ & $0.4(-0.07,0.03)$ \\
\hline
\end{tabular}

^For difference between means/medians. 

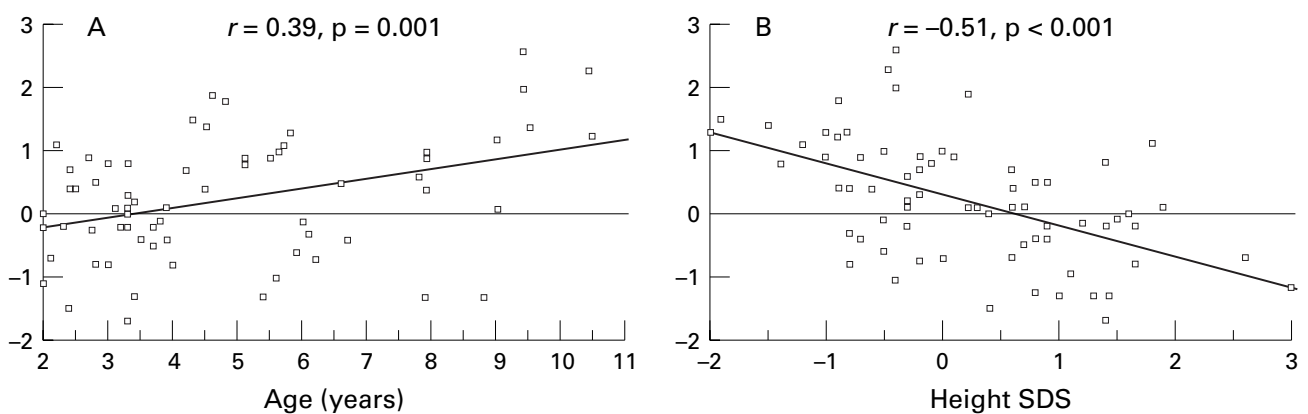

Figure 1 Relation between delay in bone age in children with atopic dermatitis and (A) age and (B) height SDS at study entry. The bold lines are the regression lines.

and three controls had height SDS less than -1.96 of the mean.

Height velocity SDS (table 2) did not differ between the two groups. Two of 70 and one of 64 controls had a year 1 or year 2 height velocity SDS of less than -1.96 , respectively. Three of 53 and six of 36 patients had a year 1 or year 2 height velocity SDS less than -1.96 , respectively. The latter number was significantly greater $(z=2.84 ; p=0.004)$ than the corresponding number of controls.

Height SDS at study entry $(r=-0.37$; $\mathrm{p}=0.003)$ and height velocity SDS over two years $(r=-0.31 ; \mathrm{p}=0.03)$ correlated inversely with age in patients but not in controls.

DELAY IN BONE AGE IN PATIENTS WITH ATOPIC DERMATITIS

The mean (SD) delay in bone age compared with chronological age at the start of year 1 and year 2 was 0.22 years $(0.94)$ and 0.41 years (1.27), respectively. The delay in bone age correlated with age $(r=0.39 ; \mathrm{p}=0.001)($ fig $1 \mathrm{~A})$, height SDS $(r=-0.51 ; \mathrm{p} 0.001)$ (that is, the shorter the child, the greater the delay in bone age) (fig 1B), height velocity SDS ( $r=-0.32$; $\mathrm{p}=0.01)$, and duration of atopic dermatitis $(r=0.39 ; \mathrm{p}=0.001)$. Of these, height SDS and atopic dermatitis duration were the best predictors for delay in bone age by stepwise multiple regression $\left(r^{2}=34 \% ; \mathrm{p}<0.01\right)$.

INFLUENCE OF BODY SURFACE AREA INVOLVEMENT, POTENCY OF TOPICAL GLUCOCORTICOID TREATMENT, AND COEXISTING ASTHMA

Height, height velocity, and delay in bone age did not differ between patients with $<50 \%$ body surface area involvement and those with $\geqslant 50 \%$ body surface area involvement; between patients treated with mild potency topical glucocorticoids and those treated with moderate potency ones; and between patients without asthma and those with asthma.

BODY MASS INDEX SDS IN PATIENTS WITH ATOPIC DERMATITIS COMPARED WITH CONTROLS Patients had significantly higher BMI SDS than controls but triceps and subscapular skinfold thickness did not differ (table 2). Six patients and one control were obese (BMI SDS $>+1.96)$. Five controls but only one patient were undernourished (BMI SDS <-1.96). BMI SDS of patients correlated with percentage body surface area involved $(r=0.28 ; \mathrm{p}=0.03)$ and severity of atopic dermatitis $(r=0.30$; $\mathrm{p}=0.02)$.

\section{Discussion}

Our study shows that compared with normal children, children with atopic dermatitis begin to fail in growth towards the end of the childhood component of growth. As children with atopic dermatitis approach the teenage years their height velocity decreases, the proportion of children with extremely low height velocity increases, and the delay in bone age increases. In addition, the delay in bone age is greater in children with atopic dermatitis who have lower heights and lower height velocities. Along with data suggesting that individuals with childhood onset atopic dermatitis attain normal adult height, ${ }^{5}$ these findings favour the hypothesis that children with atopic dermatitis have constitutional delay in growth. Children with asthma also have constitutional delay, with impaired growth in childhood, delayed bone age, delayed onset of puberty, but attainment of normal adult height. ${ }^{15-17}$ This growth pattern in asthma is thought to be related to the atopic state rather than asthma itself, ${ }^{18}$ and might be influenced by impaired production of adrenal androgens. ${ }^{19}$ Reduced excretion of adrenal androgens has been found in children with asthma regardless of whether they were receiving inhaled glucocorticoids. ${ }^{19}$ With a delayed pattern of growth, short stature is likely to be more pronounced during the teenage years, owing to delayed onset of puberty and the pubertal growth spurt. This would explain the normal stature of the children with atopic dermatitis in our study, who were all under 11 years of age and prepubertal, and the short stature reported in previous cross sectional studies, which included patients with atopic dermatitis who were up to 16 years of age. ${ }^{12}$

Although long term systemic glucocorticoid treatment is associated with growth suppression $^{20-22}$ and glucocorticoid preparations applied to the skin are absorbed into the bloodstream, ${ }^{23-26}$ the potential effect of topical glucocorticoid treatment on growth is unknown. In our patients, prolonged treatment with moderate potency topical glucocorticoids did not have an adverse influence on growth. In addition, as reported previously, topical glucocorticoid treatment did not suppress adrenal 
glucocorticoid function in these children with atopic dermatitis. ${ }^{27}$

Our observation of higher BMI SDS in children with atopic dermatitis compared with controls excludes undernutrition as a factor adversely affecting growth in children with atopic dermatitis. The systemic effect of topical glucocorticoid treatment and/or reduced daytime physical activity for reasons such as distress from itching or withdrawal because of teasing or self consciousness are possible explanations for the high BMI of atopic dermatitis patients.

We conclude that prepubertal children with atopic dermatitis are developing a pattern of growth delay, which is most obvious in those approaching the pubertal years. We anticipate that this group will tend to have delayed puberty, which may need therapeutic intervention, but our previous study ${ }^{5}$ suggests that final height prognosis is good.

We thank the children, parents, and staff of St Augustine's We thank the children, parents, and staff of St Augustine's Church of England Primary School and Mount Carmel Infants Foster and S Hollis for statistical advice.

Kristmundsdottir F, David TJ. Growth impairment in children with atopic eczema. $\mathcal{F} R$ Soc Med 1987;80:9-12

dren with atopic eczema. $\mathcal{F} R$ Soc Med 1987;80:9-12.
2 Pike MG, Chang CL, Atherton DJ, Carpenter RG, Preece MA. Growth in atopic eczema: a controlled study by quesMA. Growth in atopic eczema: a controlled
tionnaire. Arch Dis Child 1989;64:1566-9.

3 Massarano AA, Hollis S, Devlin J, David TJ. Growth in atopic eczema. Arch Dis Child 1993;68:677-9.

4 Voss LD, Mulligan J. Short normal stature- nature or nurture? (The Wessex growth study.) Pediatr Res 1993 33(suppl):321.

5 Patel L, Clayton PE, Jenney MEM, Ferguson JE, David TJ. Adult height in individuals with childhood onset atopic dermatitis. Arch Dis Child 1997;76:505-8.

6 Wahlgren CF. Pathophysiology of itching in urticaria and atopic dermatitis. Allergy 1992;47:65-75.

7 David TJ, Ferguson AP, Newton RW. Nocturnal growth hormone release in children with short stature and atopic dermatitis. Acta Derm Venereol Suppl (Stockh) 1991;71: 229-31.
8 David TJ. Dietary treatment of atopic eczema. Arch Dis Child 1989;64:1506-9.

9 Prader A. Delayed adolescence. Clin Endocrinol Metab 1975; 4:143-55.

10 Shalet SM. Treatment of constitutional delay in growth and puberty (CDGP). Clin Endocrinol 1989;31:81-6.

11 Cameron $\mathrm{N}$. The methods of auxological anthropometry. In: Falkner F, Tanner JM, eds. Human growth. Vol 3, 2nd ed. New York: Plenum, 1986:3-46.

12 Tanner JM, Whitehouse RH, Takaishi M. Standards from birth to maturity for height, weight, height velocity and weight velocity: British children 1965. Arch Dis Child 1966; 41:454-71, 613-35.

13 Cole TJ, Freeman JV, Preece MA. Body mass index reference curves for the UK, 1990. Arch Dis Child 1995;73: $25-9$.

14 Tanner JM, Whitehouse RH, Marshall WA, Healy MJR, Goldstein H. Assessment of skeletal maturity and prediction of adult height (TW2 method). London: Academic Press, 1975.

15 Balfour-Lynn L. Growth and childhood asthma. Arch Dis Child 1986;61:1049-55.

16 Martin AJ, Landau LI, Phelan PD. The effect on growth of childhood asthma. Acta Paediatr Scand 1981;70:683-8.

17 Hauspie R, Susanne C, Alexander F. Maturational delay and temporal growth retardation in asthmatic boys. $\mathcal{F}$ allergy Clin Immunol 1977;59:200-6.

18 Ferguson AC, Murray AB, Wah-Jun T. Short stature and delayed skeletal maturation in children with allergic disease. F Allergy Clin Immunol 1982;69:461-6.

19 Priftis K, Milner AD, Conway E, Honour JW. Adrenal function in asthma. Arch Dis Child 1990;65:838-40.

20 Preece $M$. The effect of administered corticosteroids on the growth of children. British Postgraduate Medical fournal 1976;52:625-30.

21 Reichling GH, Kligman AM. Alternate-day corticosteroid therapy. Arch Dermatol 1961;83:980.

22 Smith JM. Long term steroid treatment in asthmatic children. Ann Allergy 1965;23:492-6.

23 Wester RC, Maibach HI. Topical glucocorticoids with increased benefit/risk ratio. In: Korting HC, Maibach HI, eds. Current problems in dermatology. Vol. 21. Basel: Karger, 1993:45-60.

24 Vermeer BJ, Heremans GFP. A case of growth retardation and Cushing's syndrome due to excessive application of betamethasone-17-valerate ointment. Dermatologica 1974; 149:299-304

25 Bode HH. Dwarfism following long-term topical corticosteroid therapy. $\mathscr{F} A M A$ 1980;244:813-14

26 Turpeinen M, Salo OP, Leisti S. Effect of percutaneous ness in infants with severe skin disease. Br f Dermatol 1986; 115:475-84

27 Patel L, Clayton PE, Addison GM, Price DA, David TJ. Adrenal function following topical steroid treatment in children with atopic dermatitis. Br f Dermatol 1995;132: 950-5. 